\title{
Assessment the effect of the use of bisphosphonates on dental implant rehabilitation and peri-implant tissues
}

\author{
Rebecca Ellen Mayall, DDS ${ }^{1}$, Cimara Fortes Ferreira, DDS, MSc, PhD ${ }^{1}$, Russell Anthony \\ Wicks, DDS, $\mathrm{MSc}^{3}$, Felipe Fabrício Farias da Silva, DDS $^{4}$
}

${ }^{1}$ Assistant Professor, Department of Prosthodontics, University of Tennessee Health Sciences College of Dentistry, Memphis, TN. ${ }^{2}$ Assistant Professor, Department of Prosthodontics, University of Tennessee Health Sciences College of Dentistry, Memphis, TN. ${ }^{3}$ Professor, Chair, Department of Prosthodontics. University of Tennessee Health Sciences College of Dentistry, Memphis, TN. ${ }^{4}$ Private practice, Quixeramobim, Ceará, Brazil.

\section{ABSTRACT}

Background: Long-term use of bisphosphonates (BP) has been associated with the risk of BP-related osteonecrosis of the jaw (BRONJ). The number of post-menopausal women receiving BP therapy for osteoporosis continues to increase as the life expectancy increases. Dental implant rehabilitations have progressed over the years. The purpose of the present study was to evaluate the peri-implant conditions of patients taking oral or intravenous (IV) BPs. Methods: This was a retrospective study using an ORACLE database search by means of a Procedural Language/Structured Query engine. Fifty female patients with dental implant rehabilitations and taking bisphosphonates, and fifty female patients with dental implants but not taking BP were evaluated. Peri-implant health and rehabilitation conditions were collected and statistics analyzed. Results: Data analysis revealed a strong indication ( $p<0.01 ; 82.81 \%$ ) of the use of bisphosphonates and absence of abscesses. Relative risk indicated 25 times more chance of a person that does not use bisphosphonates to develop abscess when compared with people using bisphosphonates. This shows that the use of bisphosphonates may play a protecting role in the patients with dental implants. Alternatively, there was a strong indication $(p<0.01)$ of existence of association between the occurrence of mucositis and the use of bisphosphonates. Most of the cases of mucositis (94.44\%) occurred in patients that used bisphosphonates while the majority of the cases where mucositis did not occur $(59.76 \%)$ referred to the group being treated with bisphosphonates. Conclusion: This study revealed that there was absence of indications of significant associations between doses of bisphosphonates and the occurrence of peri-implant diseases.

Keywords: Implantology, osseointegration, osseoporosis, periodontitis. prosthodontics.

*Correspondence to Author:

Cimara Fortes Ferreira, DDS, MSc, PhD Assistant Professor, Director of Implant Dentistry, Department of Periodontology, University of Tennessee School of Dentistry, Dunn Dental Building, 875 Union Avenue Memphis, TN 38163

How to cite this article:

Rebecca Ellen Mayall, Cimara Fortes Ferreira,Russell Anthony Wicks, Felipe Fabrício Farias da Silva. Assessment the effect of the use of bisphosphonates on dental implant rehabilitation and peri-implant tissues. International Journal of Dental Research and Reviews, 2020, $3: 36$

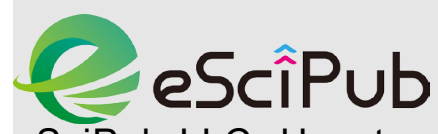

eSciPub LLC, Houston, TX USA. Website: https://escipub.com/ 


\section{INTRODUCTION}

Bisphosphonate use has long been a concern when patients also have a need for restorative work involving dental implants due to the risk of bisphosphonate-related osteonecrosis of the jaw (BRONJ). The first cases of BRONJ were reported by Marx et al in 2003. ${ }^{1}$ Also in 2003, Migliorati ${ }^{2}$ postulated that bisphosphonates may cause oral avascular bone necrosis due to antiangiogenic effect leading to inhibition of osteoclasts. ${ }^{2}$ Bisphosphonates work by inhibiting osteoclast activity, which cause bone resorption, thereby facilitating increased bone mass and thickness. ${ }^{3}$ Bisphosphonates offer major therapeutic benefits to individuals with metastatic and metabolic bone disease. ${ }^{4}$ One of these diseases is osteoporosis. Osteoporosis is a bone-resorptive, host-dependent, multifactorial and systemic skeletal disease generally affecting older females, marked by reduced bone strength, and decreased bone mineral density and deterioration of bone tissue, resulting in increased bone fragility and risk of bone fracture. ${ }^{5}$ The number of post-menopausal women receiving bisphosphonate therapy for osteoporosis continues to increase as the life expectancy increases. This also means that the patients will be required to be on bisphosphonates for an extended period of time. ${ }^{6}$

Current research has been trying to address the possible deleterious effects of the long-term use of bisphosphonates in the oral cavity ${ }^{7-12}$ It has been suggested that bisphosphonates could possibly be used in conjunction with conventional scaling and root planning to treat periodontal disease. Although the etiologies of postmenopausal osteoporosis and periodontal disease are different, the bone loss that occurs in both diseases shares several clinical features. ${ }^{13}$ Verde, et al. (2015) ${ }^{13}$ evaluated the presence of receptor activator of nuclear factor-kappa $B$ ligand (RANKL) and osteoprotegerine (OPG) in gingival crevicular fluid of patients with periodontal disease and postmenopausal osteoporosis/osteopenia. RANKL and OPG are proteins that regulate bone metabolism in periodontitis and osteoporosis. The increase in the relative expression of RANKL and a decrease in OPG can favor the balance to osteoclastogenesis and bone reabsorption. ${ }^{13}$ The authors concluded that bisphosphonates did not alter the levels of RANKL and OPG in the gingival crevicular fluid of women presenting osteoporosis/osteopenia. In addition, RANKL-OPG relative ratio was not altered in periodontal disease. ${ }^{13}$ Bhavsar, et al. $(2016)^{14}$ also observed postmenopausal women with periodontal disease who were given oral bisphosphonates along with calcium citrate and vitamin $\mathrm{D}$ daily for 12 months. ${ }^{14}$ The authors concluded that bisphosphonate therapy as an adjunct to scaling and root planning may have significant beneficial clinical effects on the periodontium of postmenopausal women with moderate to severe chronic periodontitis.

In addition to periodontal disease, other studies have aimed at evaluating the effects of bisphosphonates use in the alveolar bone. Gregic, et al. $(2016)^{15}$ used several determinants of oral health to evaluate the correlation between dental panoramic indices and bone mineral density in three groups of patients: postmenopausal women with osteoporosis, osteoporosis treated with bisphosphonates, and a control group. ${ }^{15}$ The authors suggested that bisphosphonate therapy could have a negative influence on the examined determinants of oral health in postmenopausal women with osteoporosis. ${ }^{15}$ Also pertaining to the alveolar bone, Reiss, et al. $(2015)^{16}$ identified possible risk factors in the development of oral bisphosphonate-induced osteonecrosis. After a 6-year oral-bisphosphonates therapy and a 4-year use of prednisone for treatment of pulmonary fibrosis, a patient developed BRONJ. ${ }^{16}$ This clinical case showed that the concomitant use of bisphosphonates with other medications particularly glucocorticoids needs to be researched further. ${ }^{16}$ The authors of this study concluded that the overlapping effects of bisphosphonates and glucocorticoids may act synergistically, contributing to a higher risk for the pathogenesis of osteonecrosis of the jaw. ${ }^{16}$ 
A meta-analysis ${ }^{8}$ on the effect of bisphosphonates use on implant failure rates, marginal bone loss, and postoperative infection was conducted by Chrcanovic, et al. (2016). ${ }^{8}$ It was concluded that the real effect of bisphosphonates on the osseointegration and survival of dental implants is still not well established, and postoperative infections were not examined because there was lack of information in the researched studies. ${ }^{8}$

In order to determine the risk for BRONJ, the management of patients treated with antiresorptive medication for dental implant therapy was reviewed by Walter, et al. (2016). ${ }^{17}$ The authors concluded, from 50 articles analyzed, that an individual risk assessment is essential for predicting outcomes of treatment, and that patients with osteoporosis or further wound-healing-compromising diseases require a review of all medications before implant treatment is initiated. ${ }^{17}$ The authors also suggested that bone augmentation procedures should be avoided in patients taking bisphosphonates and strongly recommended that a perioperative antimicrobial prophylaxis be utilized. ${ }^{17}$

Studies on postoperative infections in patients taking bisphosphonates succeeding implant therapy are limited. Marín-Fernández et al. $(2015)^{18}$ reported a case on a patient which received implants 2 years prior to initiating treatment with zoledronic acid and developed symptoms of BRONJ circumscribing the implant two months later. ${ }^{18}$

The same patient received additional implants afterwards and did not present signs of BRONJ during the course of treatment. The authors concluded that patients who are current or previous users of bisphosphonates and present dental implants should undergo a check-up every 6 months, due to the possibility of developing periimplantitis, which may be a clinical sign for the onset of BRONJ. ${ }^{18}$

It was previously believed that any bisphosphonate usage was a contraindication for implant placement. ${ }^{7}$ However, more recent studies have shown that the incidence of implant failure is no different in patients taking oral bisphosphonates versus the patients not taking them and that the presence of bisphosphonates may prevent implant failure..$^{11,19}$ The risks for osteonecrosis of the jaw associated with intravenous bisphosphonate therapy appear to be higher than the risks for the oral medications; however, this also needs to be further studied. ${ }^{20}$ It has been suggested that implant therapy results in a favorable outcome if the patients is on oral bisphosphonate therapy for no longer than 3 years. ${ }^{6}$

The purpose of the present study was to evaluate the peri-implant conditions and possible implant failure of patients being treated for osteoporosis either with oral or intravenous bisphosphonates.

\section{MATERIAL AND METHODS}

The present study was a result of data collection from the University of Tennessee Health Science Center College of Dentistry patient charts, by means of axiUm Dental software (Exan, British Columbia, Canada), Oracle system (Redwoodshores, CA, USA) and PL/SQL engine.

\section{Patients}

This study was approved by the UTHSC Institutional Review Board (IRB) for exempt Ethics Committee of the UTHSC College of Dentistry (number 45CFR46.101(b)(4)). One hundred charts of patients presenting dental implants were selected for this study. Patients were divided in two groups. Group 1 were 50 female patients with a history of taking bisphosphonates (i.v. or oral) and that presented rehabilitation over dental implants. Groups 2 were 50 female patients presenting rehabilitations with dental implants and that were never exposed to bisphosphonates.

\section{Search Engine}

The UTHSC College of Dentistry patient axiUm charts, which is hosted on an ORACLE database. This allowed the database search using Procedural Language/Structured Query Language (PL/SQL) engine. PL/SQL is the Oracle procedural extension of SQL, a portable, highperformance transaction-processing language. 
The keywords used were: arthritis, osteoarthritis, rheumatoid arthritis, osteoporosis, periodontitis, Actonel, Avinza, Combunox, Embeda, Endocet, Cocet, Dolophine, Reclast, Zoledronic acid, Zometa, Prolia, Denosumab, Alendronate, Atelvia, Binosto, Bovina, Fusomax, Ibandronate, Reclast, Risedronate, Forteo, Activella, Climara, Calcitonin, Duavee, Estrace, Estratab, Estrogen,
Progesterone, Fortical Evista, Menostar, Menest, Mlacalcin, Premphase, Pempro, Raloxifene.

\section{Data Sheet Preparation}

An excel data sheet was prepared for each category indicated in Table 1a.

\section{Table1a) Categories used to evaluate patient charts indicated below.}

\begin{tabular}{|c|c|}
\hline 1. Mucositis & $\begin{array}{l}1=\text { yes, } \\
0=\text { no }\end{array}$ \\
\hline 2. Peri-implantitis & $\begin{array}{l}1=\text { yes } \\
0=\text { no }\end{array}$ \\
\hline 3. Prosthetic site & $\begin{array}{l}A=\text { Anterior } \\
P=\text { Posterior }\end{array}$ \\
\hline 4. Years in service & $\begin{array}{l}1=\text { Less than } 5 \text { years, } \\
2=5 \text { years or more }\end{array}$ \\
\hline 5. Sex & $\begin{array}{l}1=\text { female } \\
0=\text { male }\end{array}$ \\
\hline 6. General health & $\begin{array}{l}1=\text { No systemic diseases } \\
O=\text { osteoporosis } \\
A=\text { arthritis, } \\
D=\text { Diabetes, } \\
H=\text { Hypertension }\end{array}$ \\
\hline 7. Use of Statins & $1=$ yes, $0=$ no \\
\hline 8. Type of Medication & Name \\
\hline 9. Dosage of Statin & $\begin{array}{l}\text { In } \mathrm{mg} / \text { day, } \\
0=\text { not reported }\end{array}$ \\
\hline 10. How long statins were taken & In years \\
\hline 11. Smoking habit & $\begin{array}{l}0=\text { non-smoker } \\
1=\text { previous smoker } \\
2=\text { smoker }\end{array}$ \\
\hline 12. Implant failures & $\begin{array}{l}1=\text { prosthetic redo } \\
0=\text { No redo }\end{array}$ \\
\hline 13. Reason for Tooth Removal & $\begin{array}{l}1=\text { Restorative (non-restorable), } \\
2=\text { Endodontic (failure) } \\
3=\text { Periodontal (hopeless) } \\
4=\text { Trauma (fracture) }\end{array}$ \\
\hline 14. Implant Placement & $\begin{array}{l}1=\text { Delayed } \\
2=\text { Immediate Implant Placement }\end{array}$ \\
\hline 15. Race & $\begin{array}{l}1=\text { Caucasian } \\
2=\text { Asian, } \\
3=\text { African-American, } \\
4=\text { non of the } 3 \text { listed }\end{array}$ \\
\hline 16. Bisphosphonates use & $\begin{array}{l}0=\text { never used } \\
1=\text { previous use } \\
2=\text { current }\end{array}$ \\
\hline 17. Biosphosphonates via & $\begin{array}{l}1=\text { enteral/oral, } \\
2=\text { Parenteral/intravenous }\end{array}$ \\
\hline 18. Prosthetic scheme & $\begin{array}{l}1=\text { freestanding } \\
2=\text { splinted } \\
3=\text { overdenture abutment }\end{array}$ \\
\hline 19. Bisphosphonates initiation date & $0=$ not reported \\
\hline 20. Bisphosphonates Termination date & $\begin{array}{l}1=\text { present } \\
0=\text { Not reported }\end{array}$ \\
\hline 21. Biosphosphonates daily dosage & In $\mathrm{mg}, 0=$ Not reported \\
\hline 22. Keratinized tissue & O: No information, Y: Presence, N: Absente \\
\hline
\end{tabular}




\section{Categories evaluated}

The patient's general health was evaluated for the following categories: absence of systemic diseases, osteoporosis, arthritis, diabetes, hypertension and absence of systemic diseases.

The patient's peri-implant health conditions were evaluated using the categories: presence or absence of bleeding on probing (BOP), highest probing depth (PD), presence or absence of keratinized tissues and presence or absence of peri-implant abscesses.

The dental implant rehabilitation conditions were evaluated according to the categories: implant failures, years in service and how many redos were necessary.

The increased risk for dental implant failure was also evaluated in the categories: prosthetic scheme (freestanding, splinted, overdenture abutment), implant position (anterior, posterior), smoker (never, past and current), reason for tooth removal.

The patient's increased risk of osteonecrosis for the use of bisphosphonates was suggested in the evaluated categories: frequency of use of bisphosphonates (never used, previous use an current user); via (enteral/oral or parenteral/intravenous), and daily dosage (in miligrams).

\section{STATISTICAL ANALYSIS}

The method of analysis consisted of one-dimensional contingency tables with the objective of characterizing the sample in relation to the observed variables and the Qui-square test was used for equality of proportions in order to complement the study. Next, differences between the stratified groups according to the use of bisphosphonates, double entry contingency tables were constructed in the application of the Fisher's exact test in order to test the null hypothesis of absence of association between the uses of bisphosphonates with the variables indicated of the study group's health. The data was processed by means of the SAS system and all the statistical tests applied used the significance level of $5 \%(=0,05)$ for the interpretation of the results.

\section{RESULTS}

Demographic classification variables are presented in Table 1.

Table 1) Frequencies, percentages and chi-square evaluation for data proportion equality for the demographic characteristic classes.

\begin{tabular}{llrrrl}
\hline \multicolumn{1}{c}{ Characteristic } & \multicolumn{1}{c}{ Class } & Frequency & Percent $(\%)$ & \multicolumn{1}{c}{ Chi-Square } \\
\hline \multirow{2}{*}{ Sex } & Female & 100 & 100.00 & $\chi^{2}: 0.00$ \\
& Male & 0 & 0.00 & $p$-value: \\
\hline \multirow{3}{*}{ Age (years) } & $58-68$ & 33 & 33.00 & \multirow{2}{*}{$\chi^{2}: 18.38$} \\
& $68-78$ & 51 & 51.00 & $p$-value: 0.0001 \\
\hline \multirow{5}{*}{ Race } & $78-88$ & 16 & 16.00 & \\
& Caucasian & 95 & 95.00 & \\
& Asian & 5 & 5.00 & $\chi^{2}: 81.00$ \\
& African-American & 0 & 0.00 & $p$-value: 0.0001 \\
\multirow{3}{*}{ Smoking habit } & Other & 0 & 0.00 & \\
& Non-smoker & 91 & 91.00 & \multirow{2}{*}{$\chi^{2}: 150.38$} \\
& Previous smoker & 8 & 8.00 & $p$-value: 0.0001 \\
& Smoker & 1 & 1.00 &
\end{tabular}

In regards to age and race, chi-square statistical analysis show strong evidence $(p<0,05)$ of differences between population proportions in the different study categories. The ages of most patients ranged from $68-78$ (51\%), 33\% were between $58-68$ and $16 \%$ were above 78 years of age. Caucasians composed of $95 \%(n=95)$ of the samples and only $5 \%(n-5)$ were Asian. There was statistical significance $(p<0.01)$ among the different classes of smokers, most of the population sample were non-smokers (91\%), $8 \%$ previous smokers and $1 \%$ smokers. 
Table 2) Frequencies, percentages and chi-square evaluation for data proportion equality for the general health characteristic classes (systemic diseases).

\begin{tabular}{|c|c|c|c|c|}
\hline Characteristic & Class & Frequency & Percent $(\%)$ & Chi-Square \\
\hline \multirow{2}{*}{ Health $(\mathrm{H})$} & Disease & 88 & 88.00 & \multirow{2}{*}{$\begin{array}{l}\chi^{2}: 57.76 \\
\text { p-value: } 0.0001\end{array}$} \\
\hline & No disease & 12 & 12.00 & \\
\hline \multirow{2}{*}{ Hypertension (H) } & No & 29 & 29.00 & \multirow{2}{*}{$\begin{array}{l}\chi^{2}: 17.64 \\
\text { p-value: } 0.0001\end{array}$} \\
\hline & Yes & 71 & 71.00 & \\
\hline \multirow[b]{2}{*}{ Diabetes (D) } & No & 87 & 87.00 & \multirow{2}{*}{$\begin{array}{l}\chi^{2}: 54,76 \\
\text { p-value: } 0.0001\end{array}$} \\
\hline & Yes & 13 & 13.00 & \\
\hline \multirow{2}{*}{ Osteoporosis (O) } & No & 50 & 50.00 & \multirow{2}{*}{$\begin{array}{l}\chi^{2}: 0.00 \\
\text { p-value: } 1.0000\end{array}$} \\
\hline & Yes & 50 & 50.00 & \\
\hline \multirow[b]{2}{*}{ Arthritis (A) } & No & 66 & 66.00 & \multirow{2}{*}{$\begin{array}{l}\chi^{2}: 10.24 \\
\text { p-value: } 0.0014\end{array}$} \\
\hline & Yes & 34 & 34.00 & \\
\hline \multirow{11}{*}{ Disease combinations } & No disease & 12 & 12.00 & \multirow{11}{*}{$\begin{array}{l}\chi^{2}: 55.98 \\
\text { p-value: } 0.0001\end{array}$} \\
\hline & $\mathrm{D}$ & 1 & 1.00 & \\
\hline & $\mathrm{H}$ & 23 & 23.00 & \\
\hline & $\mathrm{H}, \mathrm{A}$ & 12 & 12.00 & \\
\hline & $\mathrm{H}, \mathrm{D}$ & 2 & 2.00 & \\
\hline & $\mathrm{H}, \mathrm{O}$ & 7 & 7.00 & \\
\hline & $\mathrm{H}, \mathrm{O}, \mathrm{A}$ & 17 & 17.00 & \\
\hline & $\mathrm{H}, \mathrm{O}, \mathrm{A}, \mathrm{D}$ & 3 & 3.00 & \\
\hline & $\mathrm{H}, \mathrm{O}, \mathrm{D}$ & 7 & 7.00 & \\
\hline & $\mathrm{O}$ & 14 & 14.00 & \\
\hline & $\mathrm{O}, \mathrm{A}$ & 2 & 2.00 & \\
\hline
\end{tabular}

Eighty-eight percent $(n=88)$ of the sample population present at least one of the specific diseases (hypertension, diabetes, osteoporosis or arthritis), while the remaining $12 \%(n=12)$ does not present any of the studied disease. The Chisquare test provides strong indication $(p<0.001)$ that the proportion of the population without systemic disease is significantly smaller than the population with some disease. This signifies that the differences in the proportions is not by chance. In regards to each one of the diseases, hypertension is the most recurrent among the diseases listed, having strong indication $(p<0.01)$ that the number of people with hypertension is higher than the number of people without hypertension. Alternatively, the $(13 \%)$ of people with diabetes show strong indication strong indication $(p<0.01)$ to be a significantly less proportion of the study population in comparison to $87 \%$ of people without diabetes. This result is very similar to the arthritis group, where the group with arthritis (34\%) is significantly smaller $(p<0.01)$ than the group with arthritis $(66 \%)$. In regards to osteoporosis, $50 \%$ of the patient population was selected for osteoporosis, while the other $50 \%$ were selected for not having osteoporosis in order to participate in this study. In regards to the frequencies of the systemic diseases studied, hypertension $(23 \%)$ is the most frequent. The second most frequent condition is of the group with hypertension, osteoporosis and arthritis that compose $17 \%$ of the sample size. The third most common disease is osteoporosis, which is $14 \%$ of the cases. Lastly, the fourth most common disease frequency is the $12 \%$ of the group which presents the combination of hypertension, arthritis and absence of systemic diseases. All the other combinations show, isolated, low expression, since it occurs in less than $10 \%$ of the study group and all cases together add up to $22 \%$ of the samples in the 6 categories.

The characterization of this study group's dental implants is depicted in Table 3. 
Table 3) Frequency, percentages and Chi-square test for equality of data proportions in the classes of implant characteristics.

\begin{tabular}{llrrrl}
\hline \multicolumn{1}{c}{ Characteristic } & \multicolumn{1}{c}{ Class } & Frequency & Percent $(\%)$ & \multicolumn{1}{c}{ Chi-Square } \\
\hline \multirow{3}{*}{ Reason for tooth } & Restorative & 53 & 53.00 & \\
removal & Endodontic & 20 & 20.00 & $\chi^{2}: 48.72$ \\
& Periodontal & 22 & 22.00 & $p$-value: 0.0001 \\
& Trauma & 5 & 5.00 & \\
\hline \multirow{2}{*}{ Prosthetic site } & Anterior & 25 & 25.00 & $\chi^{2}: 25.00$ \\
& Posterior & 75 & 75.00 & $p$-value: 0.0001 \\
\hline \multirow{2}{*}{ Prosthetic scheme } & Freestanding & 82 & 82.00 & \multirow{2}{*}{$\chi^{2}: 106.58$} \\
& Splinted & 9 & 9.00 & $p$-value: 0.0001 \\
& Overdenture & 9 & 9.00 & \\
\multirow{2}{*}{ Years in service } & Less than 5 years & 52 & 52.00 & $\chi^{2}: 54.76$ \\
& 5 years or more & 48 & 48.00 & $p$-value: 0.0001 \\
\hline \multirow{2}{*}{ Implant placement } & Delayed & 87 & 87.00 & $\chi^{2}: 10.24$ \\
& Immediate & 13 & 13.00 & $p$-value: 0.0014 \\
\hline \multirow{2}{*}{ Implant failures } & No redo & 96 & 96.00 & $\chi^{2}: 84.64$ \\
& Redo & 4 & 4.00 & $p$-value: 0.0001 \\
\hline
\end{tabular}

Except for the time in use, all the other categories studied show strong indication $(p<0.01)$ of existence of differences among the proportions in the class of characteristics studied in relation to dental implants. The reason for tooth removal, the most frequent cause is non-restorability of the tooth, summing up more than half of the reasons, proportion much higher than the endodontic (20\%), periodontal (22\%) reason, which are very close percentages that are much inferior to the non-restorative cases. Lastly, small percentage of the tooth losses were due to trauma. Regarding prosthetic site, the majority of the sites where the implants were placed were in the posterior $(75 \%)$ compared to $25 \%$ in the anterior sites. In regards to the prosthetic scheme, freestanding implants $(82 \%)$ were more frequent and in greater proportion when compared to equally smaller and less frequent proportions
(18\%) of splinted implants and implants used as overdenture abutments. Time of use was the only characteristic which showed significant difference between the proportions $(p<0.05)$ since $52 \%$ of the cases had less than 5 years, while $48 \%$ of the cases had 5 years or more of use. In regards to the timing for implant placement, the greatest part of the study group (87\%) is composed of people that received delay implant placement while only $13 \%$ received immediate implant placement. Lastly, retreatment was $4 \%$ of the cases, a significantly reduced proportion of the study population, a low proportion of implant failure.

The following analysis is in regards to the use of statins, which aggregated 3 variables, of which the results are presented in Table 4.

Table 4) Frequencies, percentages and Chi-square test for equality of proportions of the study data in the classes of the statin group characteristics.

\begin{tabular}{l|l|r|r|l}
\hline \multicolumn{1}{c}{ Characteristic } & \multicolumn{1}{c|}{ Class } & Frequency & Percent $(\%)$ & \multicolumn{1}{c}{ Chi-Square } \\
\hline \multirow{2}{*}{ Statins } & No & 85 & 85.00 & $\chi^{2}: 49.00$ \\
& Yes & 15 & 15.00 & $p$-value: 0.0001 \\
\hline \multirow{2}{*}{ Medication } & Atorvastatin & 5 & 33.33 & $\chi^{2}: 1.67$ \\
& Simvastatin & 10 & 66.67 & $p$-value: 0.1967 \\
\multirow{2}{*}{ Dose } & 20 & 9 & 64.29 & $\chi^{2}: 1.14$ \\
& 80 & 5 & 35.71 & $p$-value: 0.2850 \\
\hline
\end{tabular}


There is strong indication $(p<0.01)$ that the proportion of the population that do not use $(85 \%)$ is significantly higher than that of the population that use statins $(15 \%)$. Indications were not observed of differences $(p<0.05)$ among the doses, effect of which can be associated with the medication, accept for one case in which the patient uses simvastatin, but the dose wasn't specified as being $20 \mathrm{mg} /$ day.

Therefore, the following study was of clinical health characteristics of the implants, of which the percentages and frequencies are listed in Table 5.

Table 5) Frequencies, percentages and Chi-square test for equality of proportions of the study data in the classes of characteristics of clinical health associated with the dental implants group.

\begin{tabular}{ll|rrr}
\hline \multicolumn{1}{c}{ Characteristic } & \multicolumn{1}{c|}{ Class } & Frequency & Percent $(\%)$ & \multicolumn{1}{c}{ Chi-Square } \\
\hline \multirow{2}{*}{ Keratinized Tissue } & Not specified & 49 & 98.00 & $\chi^{2}: 46.08$ \\
& Yes & 1 & 2.00 & $p$-value: 0.0001 \\
\hline \multirow{2}{*}{ Abcess } & No & 48 & 87.27 & $\chi^{2}: 30.56$ \\
& Yes & 7 & 12.73 & $p$-value: 0.0001 \\
\hline \multirow{2}{*}{ Mucositis } & No & 82 & 82.00 & $\chi^{2}: 40.96$ \\
& Yes & 18 & 18.00 & $p$-value: 0.0001 \\
\hline \multirow{2}{*}{ Periimplantitis } & No & 98 & 98.00 & $\chi^{2}: 92.16$ \\
& Yes & 2 & 2.00 & $p$-value: 0.0001 \\
\hline
\end{tabular}

In regards to the presence of keratinized tissues, there is only one case, which amounts to $2 \%$, a proportion inferior to the other class. This is a problematic result, since the other class indicates "not reported" results. The proportion of the study group without abscesses $(87.27 \%)$ is significantly higher $(p<0.05)$ than the proportion of the group with abscesses (12.73\%); very similar results to the mucositis study group, which showed strong proportion $(p<0.01)$ of the group that did not show mucositis (82\%) is significantly higher than the group that showed (18\%). Lastly, the occurrence of peri-implantitis was in only $2 \%$ of the cases, a significantly lower proportion $(p<0.01)$ when compared to the group that didn't show this disease (98\%).

Considering the aim of this study, the observed proportions are relevant, since these are the characteristics opposing to the evaluation of the use of biosphosphonates, of which the descriptions are presented in Table 6 .

The use of the bisphosphonates was classified in two forms and both are interesting due to the subsequent studies of the effect of the bisphosphonates. The originally delineated classification incorporates three classes and strong indications observed $(p<0.1)$ of existence of differences of the proportions of the three classes once the proportion of the group that never used bisphosphonates is significantly higher $(50 \%)$ than the proportion of the patient that previously used $(29 \%)$ and currently use $(21 \%)$ bisphosphonates. When grouping the ones that previously used bisphosphonates with the ones that currently use $(50 \%)$ in one category, the results are equilibrated, where $50 \%$ of the cases previously used or use bisphosphonates and 50\% have never used bisphosphonates, which would not indicate differences between the proportions of classes $(p<0.05)$. In regards to the delivery of drug use, there is strong indication $(p<0.05)$ that the enteral/oral via occurs in higher proportions $(78 \%)$ than the parenteral/intravenous via, observed in only $10 \%$ of the study group. The use of both forms if administration occurred in $12 \%$ of the cases. Lastly, in regards to the dose, there is a small proportion of the cases $(10 \%)$ show this information, since 4 cases received $150 \mathrm{mg} / \mathrm{month}$ while only 1 case $(2 \%)$ received $70 \mathrm{mg} /$ week. The dosage was not specified in a great proportion of the study group (90\%). 
Table 6) Frequencies, percentages and Chi-square test for equality of proportions of the study data in the classes of characteristics of the use of bisphosphonates.

\begin{tabular}{|c|c|c|c|c|}
\hline Characteristic & Class & Frequency & Percent $(\%)$ & Chi-Square \\
\hline \multirow{3}{*}{ Bisphosphonates use } & Never & 50 & 50.00 & \multirow{3}{*}{$\begin{array}{l}\chi^{2}: 13.46 \\
p \text {-value: } 0.0012\end{array}$} \\
\hline & Previous & 29 & 29.00 & \\
\hline & Current & 21 & 21.00 & \\
\hline \multirow{2}{*}{$\begin{array}{l}\text { Bisphosphonates use } \\
\text { (simplified) }\end{array}$} & No & 50 & 50.00 & \multirow{2}{*}{$\begin{array}{l}\chi^{2}: 0.00 \\
p \text {-value: } 1.0000\end{array}$} \\
\hline & Yes & 50 & 50.00 & \\
\hline \multirow{3}{*}{ Bisphosphonates via } & Enteral/oral & 39 & 78.00 & \multirow{3}{*}{$\begin{array}{l}\chi^{2}: 44.92 \\
p \text {-value: } 0.0001\end{array}$} \\
\hline & Parenteral/Intravenous & 5 & 10.00 & \\
\hline & Both & 6 & 12.00 & \\
\hline \multirow{3}{*}{ Bisphosphonates dose } & Not specified & 45 & 90.00 & \multirow{3}{*}{$\begin{array}{l}\chi^{2}: 72.52 \\
p \text {-value: } 0.0001\end{array}$} \\
\hline & $150 \mathrm{mg}$ once a month & 4 & 8.00 & \\
\hline & 70mg weekly & 1 & 2.00 & \\
\hline
\end{tabular}

In regards to the most specific objectives of this study, the existence of association between bisphosphonates and the variables associated with dental implant health will be analyzed.
Table 7 presents the first group of results based on the simplified distribution of the use of bisphosphonates.

Table 7) Frequencies (percentage within the class), Fisher's exact test (p), Cramer's V statistics (V) and Relative Risk (RR) for the evaluation of the association between the use of bisphosphonates (simplified) and characteristics of the diseases related to dental implants.

\begin{tabular}{|c|c|c|c|c|c|}
\hline \multirow[b]{2}{*}{ Characteristic } & \multirow[b]{2}{*}{ Class } & \multicolumn{4}{|c|}{ Bisphosphonates use } \\
\hline & & & No & & Yes \\
\hline \multicolumn{6}{|c|}{ Abscess (p: $0.0001-$ V: $-0.8281-$ RR: 25.00) } \\
\hline & No & & $(0.00)$ & 48 & $(100.00)$ \\
\hline & Yes & & (71.43) & 2 & $(28.57)$ \\
\hline \multicolumn{6}{|c|}{ Keratinized tissue (p: . - V: . - RR: .) } \\
\hline & No specified & 0 & $(0.00)$ & 49 & $(100.00)$ \\
\hline & Yes & 0 & $(0.00)$ & 2 & $(28.57)$ \\
\hline \multicolumn{6}{|c|}{ Mucositis (p: $0.0001-$ V: $-0.4165-$ RR: 17.00$)$} \\
\hline & No & 33 & $(40.24)$ & 49 & $(59.76)$ \\
\hline & Yes & 17 & (94.44) & 1 & $(5.56)$ \\
\hline \multicolumn{6}{|c|}{ Peri-implantitis (p: 0.4949 - V: -0.1429 - RR: .) } \\
\hline & No & & $(48.98)$ & 50 & $(51.02)$ \\
\hline & Yes & 2 & $(100.00)$ & 0 & $(0.00)$ \\
\hline
\end{tabular}

Initiating the interpretation of the occurrence of abscess, the Exact Fisher's test shows strong indication $(p<0.01)$ of the existence of association between abscess and the use of bisphosphonates. Cramer's coefficient $V$ shows that this association is very strong $(82.81 \%)$. Lastly, the relative risk indicates that there is 25 times more chance of a person that does not use bisphosphonates to develop abscess when compared with people using bisphosphonates. This shows that the use of bisphosphonates may play a protecting role in the patients with dental implants. The results of this statistics is due to the fact that in $100 \%$ of the cases that did not show abscesses, they were using bisphosphonates, therefore, there were no abscesses observed in the study group treated. Alternatively, when abscesses were observed in $71.43 \%$ of the time, the study group was not taking bisphosphonates compared to only $28.57 \%$ of the occurrence of the abscesses when the group was using bisphosphonates. In order to emphasize, not IJDRR: https://escipub.com/international-journal-of-dental-research-and-reviews/ 
that a large proportion of the cases showed presence of abscess when they were not taking bisphosphonates, when there was never occurrence of abscess when using bisphosphonates. Concluding the abscess occurrence analysis, the analysis of the presence of keratinized tissue was not possible due to absence of reported data. In regards to mucositis, there is a satisfactory result since the Fisher's exact test showed strong indication $(p<0.01)$ of existence of association between the occurrence of mucositis and the use of bisphosphonates. Cramer's $V$ test shows a strong association (41.65\%) and a relative risk of 17 . Note that most of the cases of mucositis (94.44\%) occurred in the study group that used bisphosphonates while the majority of the cases where mucositis did not occur $(59.76 \%)$ referred to the group being treated with bisphosphonates, which justified the risk of 17 times more of developing mucositis when not being treated with bisphosphonates when compared to the ones using this medication. Finally, the peri-implantitis evaluation is not satisfactory since the Fisher's exact test does not show evidence $(p=0.4949)$ of association between the occurrence of the disease with the use of bisphosphonates. Cramer's V coefficient is very low $(14.29 \%)$ and the most interesting relative risk (column 2) cannot be calculated due to the existence of zero values. Note that in the cases where there were absence of peri-implantitis, in spite of both being in the study group that did not take bisphosphonates, reveal a very small quantity of cases, even though the proportion which is $100 \%$ to reveal a true effect of the product.

Table 8 shows a similar approach to the previous analysis, however in this evaluation the original data of the use of bisphosphonates is used in the three categories instead of the simplified version, where the cases "previously" and "currently using" bisphosphonates data was grouped.

Table 8) Frequencies (percentage within the class), Fisher's exact test (p), Cramer's $V$ statistics (V) and Relative Risk (RR) for the evaluation of the association between the use of bisphosphonates use and the characteristics of the diseases related to dental implants.

\begin{tabular}{|c|c|c|c|c|}
\hline \multirow[b]{2}{*}{ Characteristic } & \multirow[b]{2}{*}{ Class } & \multicolumn{3}{|c|}{ Bisphosphonates use } \\
\hline & & Never & Previous & Current \\
\hline \multicolumn{5}{|c|}{ Abscess (p: $0.0001-\mathrm{V}: 0.8283)$} \\
\hline & No & $0 \quad(0.00)$ & $28 \quad(58.33)$ & $20(41.67)$ \\
\hline & Yes & $5(71.43)$ & $1 \quad(14.29)$ & $1(14.29)$ \\
\hline \multicolumn{5}{|c|}{ Keratinized tissue (p:0.4200 - V: 0.1679) } \\
\hline & No specified & $(0.00)$ & $29(59.18)$ & $20(40.82)$ \\
\hline & Yes & $0 \quad(0.00)$ & $0 \quad(0.00)$ & $1(100.00)$ \\
\hline \multicolumn{5}{|c|}{ Mucositis (p: $0.0001-\mathrm{V}: 0.4187$ ) } \\
\hline & No & 33 (40.24) & $29 \quad(35.37)$ & $20(24.39)$ \\
\hline & Yes & $17 \quad(94.44)$ & $0 \quad(0.00)$ & $1 \quad(5.56)$ \\
\hline \multicolumn{5}{|c|}{ Periimplantitis (p: 0.7071 - V: 0.1429) } \\
\hline & No & $48 \quad(48.98)$ & 29 (29.59) & $20(21.43)$ \\
\hline & Yes & $2(100.00)$ & $\begin{array}{ll}0 & (0.00)\end{array}$ & $0 \quad(0.00)$ \\
\hline
\end{tabular}

Note that the results are very similar in regards to the simplified evaluation as long as the results from the categories "Previous" and "Current" users when separated distribute in an equality proportionate manner. In this case, it is not viable to calculate the relative risks.
Next, association between the diseases and administration via of the bisphosphonates were evaluated and the results are in Table 9.

There are no observed indication of occurrence of peri-implant diseases and the use of bisphosphonates in regards to the administration via 
using Fisher's exact test $(p<0.05)$. Since this analyses is only based on the data of the patients taking bisphosphonates and the data showed very low presence of disease in the group taking bisphosphonates, it is natural the existence of indication of effect of administration via, as it was observed.
Lastly, based on Table 10 that allows the observation of association of doses of bisphosphonates and the occurrence of the peri-implant diseases.

Table 9) Frequencies (percentage within the class), Fisher's exact test (p), Cramer's V statistics (V) and Relative Risk (RR) for the evaluation of the association between the delivery of bisphosphonates and the characteristics of the diseases related to dental implants.

\begin{tabular}{|c|c|c|c|c|}
\hline \multirow[b]{2}{*}{ Characteristic } & \multirow[b]{2}{*}{ Class } & \multicolumn{3}{|c|}{ Bisphosphonates via } \\
\hline & & Enteral/oral & Both & Parenteral/Intrav. \\
\hline \multicolumn{5}{|c|}{ Abcess (p: $0.2041-\mathrm{V}: 0.2754)$} \\
\hline & No & $38(79.17)$ & $4 \quad(8.33)$ & $6(12.50)$ \\
\hline & Yes & $1(50.00)$ & $1(50.00)$ & $0 \quad(0.00)$ \\
\hline \multicolumn{5}{|c|}{ Keratinized tissue (p:1.0000 - V: 0.0759) } \\
\hline & No specified & $38(77.55)$ & $5(10.20)$ & $6(12.24)$ \\
\hline & Yes & $1(100.00)$ & $0 \quad(0.00)$ & $0 \quad(0,00)$ \\
\hline \multicolumn{5}{|c|}{ Mucositis (p:1.0000 - V: 0.0759) } \\
\hline & No & $38(77.55)$ & $5(10.20)$ & $6(12.24)$ \\
\hline & Yes & $1(100.00)$ & $0 \quad(0.00)$ & $0 \quad(0.00)$ \\
\hline \multicolumn{5}{|c|}{ Periimplantitis (p: . - V: .) } \\
\hline & No & $39(78.00)$ & $5(10.00)$ & $6(12.00)$ \\
\hline & Yes & $\begin{array}{ll}0 & (0.00)\end{array}$ & $0 \quad(0.00)$ & $0 \quad(0.00)$ \\
\hline
\end{tabular}

Table 10) Frequencies (percentage within the class), Fisher's exact test (p), Cramer's $V$ statistics (V) and Relative Risk (RR) for the evaluation of the association between the doses of bisphosphonates and characteristics of the diseases related to dental implants.

\begin{tabular}{|c|c|c|c|c|c|}
\hline \multirow[b]{2}{*}{ Characteristic } & \multirow[b]{2}{*}{ Class } & \multicolumn{4}{|c|}{ Bisphosphonates via } \\
\hline & & 0 & $150 \mathrm{mg}$ (month) & & (weekly) \\
\hline \multicolumn{6}{|c|}{ Abscess (p: $1.0000-V: 0.0680)$} \\
\hline & No & $43(89.58)$ & $(8.33)$ & 1 & $(2.08)$ \\
\hline & Yes & $2(100.00)$ & $(0.00)$ & 0 & $(0.00)$ \\
\hline \multicolumn{6}{|c|}{ Keratinized tissue (p:1.0000 - V: 0.0476) } \\
\hline & No specified & $44(89.80)$ & $4 \quad(8.16)$ & 1 & $(2.04)$ \\
\hline & Yes & $1(100.00)$ & $(0.00)$ & 0 & $(0.00)$ \\
\hline \multicolumn{6}{|c|}{ Mucositis (p:0.1000 - V: 0.4845) } \\
\hline & No & $45(91.84)$ & $3 \quad(6.12)$ & 1 & $(2.04)$ \\
\hline & Yes & $0 \quad(0.00)$ & $1(100.00)$ & 0 & $(0.00)$ \\
\hline \multicolumn{6}{|c|}{ Periimplantitis (p: . - V: .) } \\
\hline & No & $45(90.00)$ & $(8.00)$ & 1 & $(2.00)$ \\
\hline & Yes & $0 \quad(0.00)$ & $0 \quad(0.00)$ & 0 & $(0.00)$ \\
\hline
\end{tabular}

Likewise, in this case there weren't indications of significant associations between doses of bisphosphonates and the occurrence

\section{DISCUSSION}

This is a transversal study of observational nature, the sample was taken from a population that represents diverse defined extracts of the population observed in a period of 6 months. This study used a relatively small database 
acquired from a small data bank, which does not characterize a randomized sample. The observational nature of the study does not allow the authors to establish cause and effect. Therefore, it is reasonable to use association reports.

The literature shows survival and failure rates of implants placed in patients taking BPs that vary from $88.4-96.0 \%, 0.3$ to $3.7 \%$, respectively. Zahid, et al ${ }^{9}$ reviewed twenty-six patients on oral $\mathrm{BP}$ received a total of 51 dental implants. Three implants failed, yielding success rates of $94.1 \%$ and $88.4 \%$ for the implant-based and subjectbased analyses. According to Wagenberg, et al ${ }^{10}$ conducted a retrospective study on survival rates of immediate implant placements into fresh extraction sockets of patients on oral BP. Their overall implant survival rate was $96.0 \%$ with a failure rate of $3.7 \%$ pre-restoration and $0.3 \%$ post-restoration. Kasai, et al ${ }^{12}$ compared 35 dental implants placed in 11 patients taking BP for more than 3 years with 161 dental implants placed in 40 patients not taking BP. Five implants failed, giving a success rate of $85.7 \%$ (in comparison with $95.7 \%$ for the control group). In a retrospective study, Bell and Bell ${ }^{11}$ reported a $95 \%$ success rate following placement of $101 \mathrm{im}$ plants in 41 patients taking BP. Five implants failed; however, those were assumed to be a result of placing the implants in the posterior maxilla and positive smoking status. In the present study, patients on oral BP have shown a failure rate of $4 \%$, which is consistent with previous studies. ${ }^{9-12}$ This finding coincides with a review that Grant, et al ${ }^{6}$ conducted of 115 individuals ( $n=468$ implants) who reported that they had received oral bisphosphonate therapy. The patients were treated with Actonel, Fosamax, or Boniva. No evidence of BRONJ in any of the patients evaluated in the clinic and those contacted by phone or e-mail reported no symptoms. ${ }^{6}$ In elderly nursing home patients receiving once-yearly IV bisphosphonate zoledronic acid to prevent osteoporosis, Famili $(2013)^{5}$ found that in these 252 patients followed for one year after treatment, no osteonecrosis of the jaw had been observed. A two-year follow-up on twenty of the patients showed no failing implants. ${ }^{5}$

Data analysis revealed a strong indication $(p<0.01 ; 82.81 \%)$ of the absence of association between abscesses and the use of bisphosphonates. Relative risk indicated 25 times more chance of a person that does not use bisphosphonates to develop abscess when compared with people using bisphosphonates. According to Marx, et al (2005) ${ }^{21}$ who reviewed 119 cases of BRONJ in patients prescribed IV bisphosphonates, the complete prevention of this complication is not currently possible. ${ }^{21}$ Of the 119 cases in this study, 3 were being treated exclusively for osteoporosis with the remaining 116 given IV bisphosphonates in conjunction with chemotherapy for metastatic cancer and multiple myeloma. $13.4 \%$ presented with abscessed teeth but the study does not specify if this number includes only patients with osteoporosis. ${ }^{21}$ There are not a lot of studies examining this association and more research is necessary

$\mathrm{BP}$ have shown to play a protecting role in the patients with dental implants. Walter et al., ${ }^{17}$ reviewed approximately 50 articles where BPs were given to patients presenting only osteoporosis. These patients did not present BRONJ. Bhavsar, et al. ${ }^{14}$ found that osteoporotic postmenopausal women taking BP in addition to being treated for periodontitis had increased bone height and density over 12 months from baseline. Verde, et al. ${ }^{13}$ discovered that the addition of bisphosphonates did not help or harm the patient's peri-implant tissues or slow the progression of periodontitis. The present study strongly suggests that the use of bisphosphonates may play a protecting role in the patients with dental implants. However, the literature shows to be divergent in the possible effects of BP on dental implant therapy. Yip, et al. (2012) 22 indicated in a case-control study of 337 female patients, that patients receiving implants while taking oral bisphosphonates were 2.69 times more likely to experience failure.

The effects of BP in the periodontal and peri-implant tissues have been studied by Grgic et al. 
(2016). ${ }^{15}$ Forty-five women with osteoporosis treated with BP showed significantly higher gingival bleeding, bleeding index, and deeper pocket depths than the control and/or osteoporosis group not being treated out of 120 women. The present study does not concur with Grgic. et al. (2016). ${ }^{15}$ Alternatively, there was a strong indication $(p<0.01)$ of existence of association between the occurrence of mucositis and the use of bisphosphonates. Most of the cases of mucositis $(94.44 \%)$ occurred in patients that used bisphosphonates while the majority of the cases where mucositis did not occur $(59.76 \%)$ referred to the group being treated with bisphosphonates. According to Pereira, et al. (2015), ${ }^{23}$ the presence of gingivitis is associated with the disease osteoporosis and not limited to bisphosphonate users only. Their study investigated the possible association between periodontal changes and osteoporosis in postmenopausal women, and it was found that the women who had normal initial bone condition that progressed to osteopenia and eventually osteoporosis showed a significant increase in gingival bleeding index. ${ }^{23}$

\section{CONCLUSION}

Within the limitations of this study, the authors suggest that there were no indications of significant associations between doses of bisphosphonates and the occurrence of peri-implant diseases. This shows that the use of bisphosphonates may play a protecting role in the patients with dental implants.

\section{REFERENCES}

1. Marx RE. Pamidronate (Aredia) and zoledronate (Zometa) induced avascular necrosis of the jaws: a growing epidemic. $J$ Oral Maxillofac Surg 2003;61:1115-1117.

2. Migliorati CA. Bisphosphanates and oral cavity avascular bone necrosis. J Clin Oncol 2003;21:4253-4254.

3. Hampson G, Fogelman I. Clinical role of bisphosphonate therapy. Int $J$ Womens Health 2012;4:455-469.

4. Hoff AO, Toth B, Hu M, Hortobagyi GN, Gagel RF. Epidemiology and risk factors for osteonecrosis of the jaw in cancer patients. Ann N Y Acad Sci 2011;1218:47-54.

5. Famili N. Oral Bisphosphonates and Relationship to ONJ and Dental Implants. Dentistry 2013:1.

6. Grant BT, Amenedo C, Freeman K, Kraut RA. Outcomes of placing dental implants in patients taking oral bisphosphonates: a review of 115 cases. J Oral Maxillofac Surg 2008;66:223-230.

7. Tong N. Osseointegrated implants, osteoporosis and bisphosphonate therapy: a literature review. . Dentistry 2016:34-40.

8. Chrcanovic BR, Albrektsson T, Wennerberg A. Bisphosphonates and dental implants: A meta-analysis. Quintessence Int 2016;47:329-342.

9. Zahid TM, Wang BY, Cohen RE. Influence of bisphosphonates on alveolar bone loss around osseointegrated implants. J Oral Implantol 2011;37:335-346.

10. Wagenberg B, Froum SJ. A retrospective study of 1925 consecutively placed immediate implants from 1988 to 2004. Int $J$ Oral Maxillofac Implants 2006;21:71-80.

11. Bell BM, Bell RE. Oral bisphosphonates and dental implants: a retrospective study. J Oral Maxillofac Surg 2008;66:1022-1024.

12. Kasai T, Pogrel MA, Hossaini M. The prognosis for dental implants placed in patients taking oral bisphosphonates. J Calif Dent Assoc 2009;37:39-42.

13. Verde ME, Bermejo D, Gruppi A, Grenon M. Effect of Bisphosphonates on the Levels of Rankl and Opg in Gingival Crevicular Fluid of Patients With Periodontal Disease and Postmenopausal Osteoporosis. Acta Odontol Latinoam 2015;28:215-221.

14. Bhavsar NV, Trivedi SR, Dulani K, Brahmbhatt N, Shah S, Chaudhri D. Clinical and radiographic evaluation of effect of risedronate $5 \mathrm{mg}$ as an adjunct to treatment of chronic periodontitis in postmenopausal women (12-month study). Osteoporos Int 2016;27:2611-2619.

15. Grgic O, Kovacev-Zavisic B, Veljovic T, Novakovic-Paro J, Maravic T, Bajkin B. The influence of bone mineral density and bisphosphonate therapy on the determinants of oral health and changes on dental panoramic radiographs in postmenopausal women. Clin Oral Investig 2017;21:151-157. 
16. Reiss S, Sultan D. Risk Factors in the Development of Oral Bisphosphonateinduced Osteonecrosis. NY State Dent J 2015;81:30-33.

17. Walter C, Al-Nawas B, Wolff T, Schiegnitz E, Grotz KA. Dental implants in patients treated with antiresorptive medication - a systematic literature review. Int J Implant Dent 2016;2:9.

18. Marin-Fernandez $A B$, Garcia Medina $B$, Aguilar-Salvatierra A, Jimenez-Burkhardt A, Gomez-Moreno G. Jaw osteonecrosis management around a dental implant inserted 2 years before starting treatment with zoledronic acid. J Clin Exp Dent 2015;7:e444446.

19. Martin DC, O'Ryan FS, Indresano AT, et al. Characteristics of implant failures in patients with a history of oral bisphosphonate therapy. J Oral Maxillofac Surg 2010;68:508-514.

20. Mattheos N, Caldwell P, Petcu EB, Ivanovski $S$, Reher P. Dental implant placement with bone augmentation in a patient who received intravenous bisphosphonate treatment for osteoporosis. J Can Dent Assoc 2013;79:d2.

21. Marx RE, Sawatari Y, Fortin M, Broumand V. Bisphosphonate-induced exposed bone (osteonecrosis/osteopetrosis) of the jaws: risk factors, recognition, prevention, and treatment. $J$ Oral Maxillofac Surg 2005;63:1567-1575.

22. Yip JK, Borrell LN, Cho SC, Francisco $\mathrm{H}$, Tarnow DP. Association between oral bisphosphonate use and dental implant failure among middle-aged women. J Clin Periodontol 2012;39:408-414.

23. Pereira FM, Rodrigues VP, de Oliveira AE, Brito LM, Lopes FF. Association between periodontal changes and osteoporosis in postmenopausal women. Climacteric 2015;18:311-315. 